\title{
PERAN PRODUCT CUES AND RISK AVERSION PADA PURCHASE INTENTION DAN POST PURCHASE FEELINGS
}

\author{
Sri Rejeki Ekasasi \\ STIM-YKPN Yogyakarta \\ e-mail: sekasasi@yahoo.com \\ Ayu Hema Ajeng Diwasasri \\ International Program, School of Business and Economics Universitas Islam Indonesia \\ e-mail: ayuhema1@gmail.com
}

\begin{abstract}
The research aimed to investigate the influence of extrinsic cues and intrinsic cues and risk aversion towards purchase intention and post-purchase feeling of counterfeited computer software and music CD. This research study collected data from two populations which are students and employee. Approximately 128 respondents involved to give respond for the survey. The analysis using Structural Equation Model (SEM) show that product cues and risk aversion give different significant impact towards purchase intention and post-purchase feeling of counterfeited computer software and music CD. The research concluded that risk aversion and extrinsic cues has a significant influence to purchase intention of counterfeited computer software while it does not appear similar result to music CD. Moreover, the study revealed that for both counterfeited computer software and music $C D$, the purchase intention is proven to have negative significant influence towards post-purchase feelings.
\end{abstract}

Keywords: risk aversion, extrinsic cues, intrinsic cues, purchase intention, post-purchase feelings

\begin{abstract}
Abstrak
Tujuan dari penelitian ini adalah untuk melihat pengaruh atribut ekstrinsik dan intrinsic produk serta aspek menolak resiko terhadap niat beli dan perasaan paska beli software computer dan CD music bajakan. Penelitian ini diharapkan akan memperoleh sebuah model dengan pendekatan cultural dan strategi bisnis untuk memblokir atau mengurangi produk bajakan yang dapat diakses konsumen di pasar. Data primer akan dikumpulkan dari dua populasi, kelompok mahasiswa dan kelompok pekerja, dari empat kota besar di Indonesia yaitu Jakarta, Semarang, Surabaya, dan Yogyakarta. Lebih kurang 128 responden terlibat dalam penelitian ini. Hasil penelitian menunjukkan bahwa aspek atribut produk yang bersifat ekstrinsik dan aspek menolak resiko terbukti memiliki hubungan signifikan mempengaruhi niat beli software computer, akan tetapi lain tidak demikian pada niat beli CD music bajakan. Lebih lanjut, hasil penelitian menunjukkan bahwa niat beli produk bajakan memiliki hubungan negatif yang signifikan terhadap perasaan paska beli software computer dan CD music bajakan.
\end{abstract}

Keywords: aspek menolak resiko, atribut ekstrinsik produk, atribut intrinsik produk, niat beli, perasaan paska beli

\section{PENDAHULUAN}

Pembajakan produk pada dasarnya adalah menggunakan tanpa ijin pemegang merek atau hak atas kekayaan intelektual (intellectual ownership) yang syah. Secara fisik, pembajakan ini merupakan tindakan meniru atau mengkopi produk asli (pemegang merek asli) dan memasarkannya. Biasanya produk yang 
dikopi merupakan produk-produk terkenal. Pada umumnya yang dikopi adalah pembungkusan dan bahan bakunya yang dibuat sedemikian rupa sehingga menyerupai aslinya (Lynch, 2002), termasuk juga didalamnya pemalsuan trademark beserta pelabelannya (Ang et al., 2001; dan Phau et al., 2001). Oleh karena itu, secara umum, pembajakan produk didefinisikan sebagai upaya mengkopi/memalsu produk, bungkus dan konfigurasi yang berkaitan dengan produk tersebut sehingga seperti produk aslinya, serta memasarkannya untuk keuntungan sendiri (Lynch, 2002).

Pada dasarnya ada dua jenis pembeli produk bajakan, pembeli yang tidak tahu kalau produk yang dibeli adalah produk bajakan dan pembeli yang tahu kalau produk yang dibeli produk bajakan (Chakraborty et al., 1996). Konsumen yang sadar bahwa produk yang dibeli adalah bajakan, maka konsumen akan mempertimbangkan dengan sadar harga, kualitas dan pasar tempat tersedianya produk tersebut. Nampaknya konsumen yang sadar membeli produk bajakan karena pertimbangan harga yang murah. Mereka sangat sadar akan resiko yang diperoleh dengan produk bajakan ini sehingga produk yang dibeli selalu dipertimbangkan berkaitan dengan keselamatan konsumen (Chakraborty et al., 1996; dan Delener, 2000).

Belum kuatnya proteksi secara global hak atas kekayaan intelektual telah merugikan banyak industri pemegang merek resmi. Produk yang dibajakpun banyak ragamnya, mulia dari produk makanan sampai dengan produk bertehnologi (Harvey and Ronkainen, 1985; Chaudhry and Walsh, 1996; dan Delener, 2000). Biaya produksi sangat murah dan pembajak merasa aman melakukan kejahatannya, akibatnya usaha pembajakan menjadi menjamur dimana-mana, dan menjadi problem serius bagi pemegang merek resmi dan pemerintah (Delener, 2000). Namun demikian, Indonesia sebagai Negara yang masuk dalam daftar yang selalu diawasi oleh Amerika dalam persoalan yang berkaitan dengan HaKI masih belum banyak penelitian yang menyentuh pada bidang ini. Sehingga penelitian ini penting dilakukan agar iklim penelitian dapat disesuaikan dengan kondisi yang terjadi di Indonesia. Ada dua tujuan utama penelitian. Pertama, untuk mengetahui pengaruh atribut ekstrinsik dan intrinsic produk terhadap niat beli dan perasaan paska beli software komputer dan CD musik bajakan. Dari tujuan yang pertama ini diharapkan diperoleh sebuah model dengan pendekatan kultural meredam penggunaan produk bajakan. Kedua, untuk melihat pengaruh aspek menolak resiko terhadap niat beli dan perasaan paska beli software komputer dan CD music bajakan. Dari tujuan yang kedua ini di harapkan diperoleh sebuah strategi bisnis untuk memblokir atau mengurangi produk bajakan yang dapat diakses konsumen di pasar.

\section{KAJIAN PUSTAKA DAN PENGEMBANGAN HIPOTESIS}

The Theory of Planned Behavior oleh Ajzen and Fishbein (1980) merupakan pengembangan dari Theory of Reasoned Action dengan memperhitungkan control perilaku (perceived behavioral control) sebagai sebuah determinan untuk menyatakan kecenderungan melakukan sebuah perilaku dan melaksanakan perilaku tersebut. Dalam perspektif teori ini menunjukkan bahwa keinginan konsumen membeli produk bajakan dipengaruhi juga oleh kesadaran norma hukum yang berkaitan dengan pelanggaran pemalsuan produk. Namun keinginan membeli juga dipengaruhi oleh dua faktor yaitu permintaan produk bajakan dan kualitas produk bajakan. Dari perspektif konsep marketing, konsumen memiliki kebutuhan dasar yang harus dipenuhi (Kotler et al., 2001). Kebutuhan dasar tersebut selanjutnya menciptakan permintaan konsumen terhadap produk dan jasa, karenanya mempengaruhi perilaku pembelian konsumen.

\section{Atribut Ekstrinsik dan Intrinsik Produk}

Cue utilization theory mengatakan bahwa predictive value dan confidence value merupakan indicator kualitas sebuah produk atau penjual. Predictive value merupakan ekspektasi konsumen terhadap kualitas barang, sedangkan confidence value merupakan keyakinan konsumen terhadap kualitas sebuah barang. Ekstrinsik indicator dapat dilihat sebagai atribut 
yang berada diluar fisik produk tersebut, seperti harga, merek, pembungkusan, penjual dan sebagainyanya. Sedangkan intrinsic indicator merupakan atribut produk yang melekat dalam fisik produk tersebut, seperti proses pembuatan, bahan baku, bumbu campuran, garansi, dan sebagainyanya. Temuan penelitian terdahulu telah melihat adanya indicator kualitas dalam persepsi konsumen ketika menilai sebuah produk, baik secara ekstrinsik (Leavitt, 1954; Allison and Uhl, 1962; McDaniel and Baker, 1977; danWheatley et al., 1977) maupun intrinsik (Olson, 1972; Olson \& Jacoby, 1972). Namun demikian, peneitian terdahulu dikaitkan pada persepsi konsumen dengan produk original. Karenanya sangat menarik untuk dikaji bagaimana produk bajakan di persepsikan oleh konsumennya. Penelitian ini menduga bahwa karena secara intrinsic produk bajakan kualitasnya akan sangat diragukan maka konsumen melihat kualitas produk bajakan akan sangat tergantung dengan atribut ekstrinsiknya (Hidayat, 2008). Oleh karena itu, penelitian ini mengajukan hipotesis sebagai berikut:

H1a: Semakin tinggi konsumen mengevaluasi atribut ektrinsik produk bajakan semakin tinggi niat konsumen membeli membeli software bajakan.

H1b: Semakin tinggi konsumen mengevaluasi atribut ektrinsik produk bajakan semakin tinggi niat konsumen membeli membeli CD musik bajakan.

$\mathrm{H} 2 \mathrm{a}$ : Semakin tinggi konsumen mengevaluasi atribut intrinsik produk bajakan semakin rendah niat konsumen membeli software bajakan.

$\mathrm{H} 2 \mathrm{~b}$ : Semakin tinggi konsumen mengevaluasi atribut intrinsik produk bajakan semakin rendah niat konsumen membeli $\mathrm{CD}$ musik bajakan.

\section{Sikap Menolak Resiko}

Menolak resiko dalam penelitian ini adalah dalam kaitannya dengan toleran terhadap kerugian yang mungkin akan dihadapi jika konsumen melakukan pembelian atau mengkopi sebuah prduk perangkat lunak bajakan. Menolak Resiko merupakan variable penting dalam marketing ketika seorang konsumen melakukan keputusan beli (Bauer, 1960; dan Cox, 1967). Dalam kasus pembajakan produk, strategi untuk mengurangi resiko bisa bermacam-macam. Biasanya konsumen akan bergantung pada factor ekstrinsiknya, misalnya bergantung dengan penegecer yang bereputasi, brand yang sudah terkenal atau mencari harga yang paling murah (Roselius, 1971). Akan tetapi, faktanya bahwa memperhitungkan sebuah resiko dalam pengambilan keputusan bisa berdimensi banyak, misalnya resiko social, financial, fisikal, psikologis dan sebagainyanya (Jacoby dan Kaplan, 1972). Secara natural, konsumen melakukan penilaian terhadap sebuah produk bajakan akan juga memperhitungkan resiko yang kemungkinan akan di tanggung ketika keputusan membeli produk bajakan. Artinya, profil sebuah produk bajakan harus benar-benar dipahami dan dapat diterima untuk digunakan dengan resiko yang paling minimal.

H3a: Semakin tinggi konsumen mempertimbangkan resiko semakin rendah niat konsumen membeli software bajakan.

H3b: Semakin tinggi konsumen mempertimbangkan resiko semakin rendah niat konsumen membeli CD musik bajakan.

\section{Niat Beli dan Perasaan Paska Beli}

Semakin banyak kesempatan konsumen mengevaluasi produk bajakan, semakin besar niat konsumen membeli produk bajakan (Nia and Zaichkowsky, 2000; Cordell et al., 1996). Disisi lain, ketika mereka jadi membeli produk bajakan tersebut, penelitian sebelumnya mengatakan bahwa pasca-pembelian produk bajakan ada sebagian konsumen yang memiliki perasaan negatif bersalah, tidak etis, dan ilegalitas yang terkait dengan persepsi dan sikap terhadap produk-produk palsu (Chakraborty et al.,1997; Chakraborty, Allred and Bristol, 1996), Akibatnya, diharapkan bahwa semakin besar persepsi konsumen tentang produk palsu, semakin sedikit responden akan merasa bersalah.

H4a: Semakin besar niat konsumen membeli produk bajakan, semakin rendah perasaan bersalah paska beli software bajakan.

H4b: Semakin besar niat konsumen membeli produk bajakan, semakin rendah perasaan bersalah paska beli CD musik bajakan. 


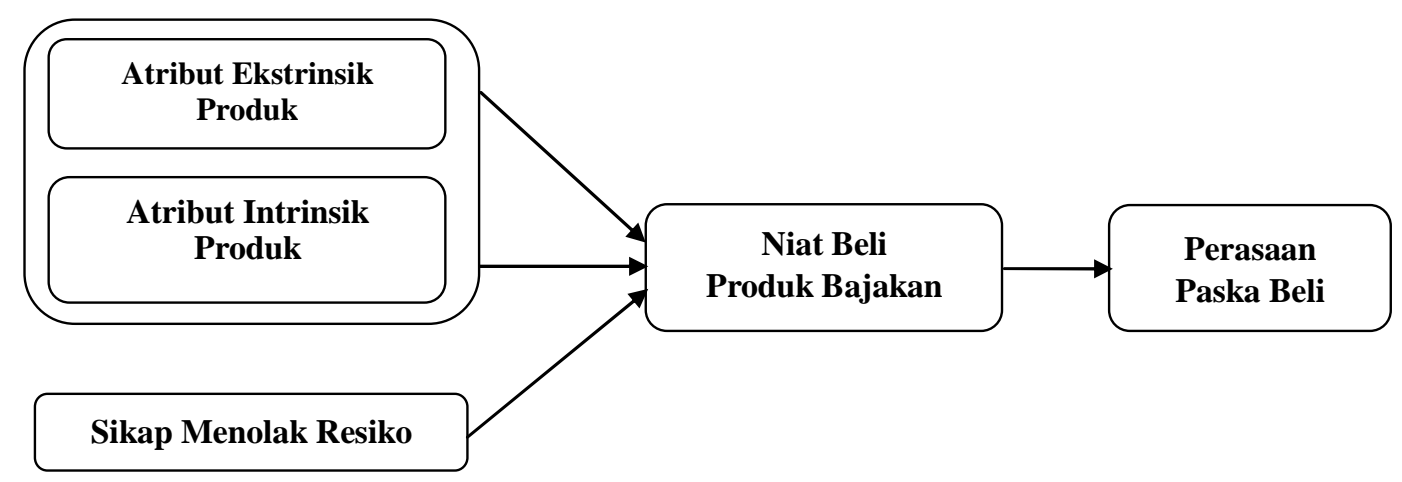

Gambar 1: Kerangka Konseptual Penelitian

\section{METODE PENELITIAN}

Data primer yang akan dikumpulkan merupakan representasi dari kelompok mahasiswa. Data akan di kumpulkan dengan menggunakan daftar pertanyaan atau kuestioner, dengan sampel penelitian menggunakan responden mahasiswa dan pekerja. Sampel akan di ambil secara simple convenience sampling karena populasi dari konsumen yang menjadi objek penelitian ini bersifat homogen 12 pada setiap populasinya, sehingga setiap elemen didalam populasi dapat dikenal dan memiliki kesempatan yang sama untuk dipilih sebagai respondent (Sekaran, 2000). Adapun dalam melakukan estimasi pada study awal ini teknik pengujian yang dilakukan yaitu menggunakan analisis model jalur (path model) dengan menggunakan aplikasi Smart PLS sebagai alat analisis untuk melakukan prediksi awal atas studi yang dilakukan. Dalam proses estimasi model yang dilakukan pada studi awal ini metode umum yang digunakan dalam membentuk model jalur yang digunakan secara teknis berupa hubungan konstruk laten yang terdiri dari beberapa indikator pengukuran. Total jumlah responden yang diperoleh sebanyak 152 responden, namun data yang bisa di gunakan untuk analisis sebanyak 128 buah, sisanya rusak karena tidak lengkap dan salah pengisian. Data yang telah diuji validitas dan reliabilitas lalu selanjutnya diolah menggunakan Structural Equation Modelling (SEM) untuk uji hipotesis.

Kuesioner disusun dengan skala likert yang diadaptasi dari Huang et al. (2004), Donthu and Garcia (1999), Field (2000), Phau and Teah (2009), Ang et al. (2001), De Matos et al. (2007), Maldonado and Hume (2005), dimana bahasa inggris yang digunakan sebagai bahasa dalam kuesioner. Akan tetapi, kuesioner yang dipakai dalam penelitian ini disusun dalam bahasa Indonesia untuk memperjelas pemahaman bagi responden. Kuesioner disusun dalam 10 bagian, termasuk di dalamnya bagian yang memuat informasi demografi responden. Deskripsi skala pengukuran, jumlah item pertanyaan dan reliabilitas item ditunjukkan pada Tabel 1. Keseluruhan item dalam instrument penelitian diukur menggunakan 7 skala likert, dengan 1 merepresentasikan "sangat rendah" dan 7 merepresentasikan "sangat tinggi."

\section{HASIL PENELITIAN Analisis Deskriptif}

Total sampel yang dipakai dalam penelitian ini berjumlah 128 responden. Mayoritas responden dengan jenis kelamin laki - laki (58.2\%) dan sisanya merupakan responden dengan jenis kelamin perempuan (41.8\%). Responden didominasi oleh usia dengan rentang 20-30 tahun (69.5\%), lalu usia 41-50 tahun (11.3\%) dan usia dibawah 20 juga usia 31-40 tahun membagi persentase yang sama $(8.5 \%)$. Hasil tersebut memperlihatkan bahwa pengguna produk software komputer bajakan cenderung didominasi oleh responden dengan usia produktif yang memiliki kemampuan lebih baik dalam memahami dan menggunakan software komputer bajakan. Selanjutnya, mayoritas responden memiliki status sudah menikah (61.7\%) dengan dominasi penghasilan kurang dari 24 
juta $(61.7 \%)$. Sebagian besar responden juga percaya bahwa tidak ada keterkaitan antara pembelian produk bajakan dengan agama atau kepercayaan yang dianut seseorang $(55.3 \%)$.

\section{Uji Kebaikan Model (Goodness of Fit)}

Untuk mengetahui kriteria model yang baik (Goodness of Fit) digunakan: Absolut Fit Measured (pengukuran indeks mutlak), Incremental Fit Measured (Pengukuran tambahan indeks) dan Parsimonious Fit Measured (Peng- ukuran kesederhanaan indeks). Uji kebaikan model ini menggunakan software Amos versi 6.0. Hasil uji kebaikan model disajikan dalam Tabel 1.

Dari hasil pengukuran Goodness of Fit Index pada tabel di atas, dapat disimpulkan bahwa seluruh parameter telah memenuhi persyaratan yang diharapkan, dengan demikian model dapat digunakan untuk tahap selanjutnya yaitu uji hipotesis.

Tabel 1: Hasil Uji Kebaikan Model (Goodness of Fit Test)

\begin{tabular}{lccc}
\hline \multicolumn{1}{c}{ Goodness of Fit Index } & Hasil & Cut Off Value & Kriteria \\
\hline Likelihood Chi Square & 315.194 & Diharapkan kecil & Baik \\
Probability & 0,168 & $\geq 0,05$ & Baik \\
CMIN/DF & 1,079 & $\leq 2,00$ & Baik \\
RMSEA & 0,047 & $\leq 0,08$ & Baik \\
GFI & 0,926 & $\geq 0,90$ & Baik \\
AGFI & 0,910 & $\geq 0,90$ & Baik \\
TLI & 0,935 & $\geq 0,90$ & Baik \\
CFI & 0,966 & $\geq 0.90$ & Baik \\
\hline
\end{tabular}

\section{Hasil Uji Hipotesis}

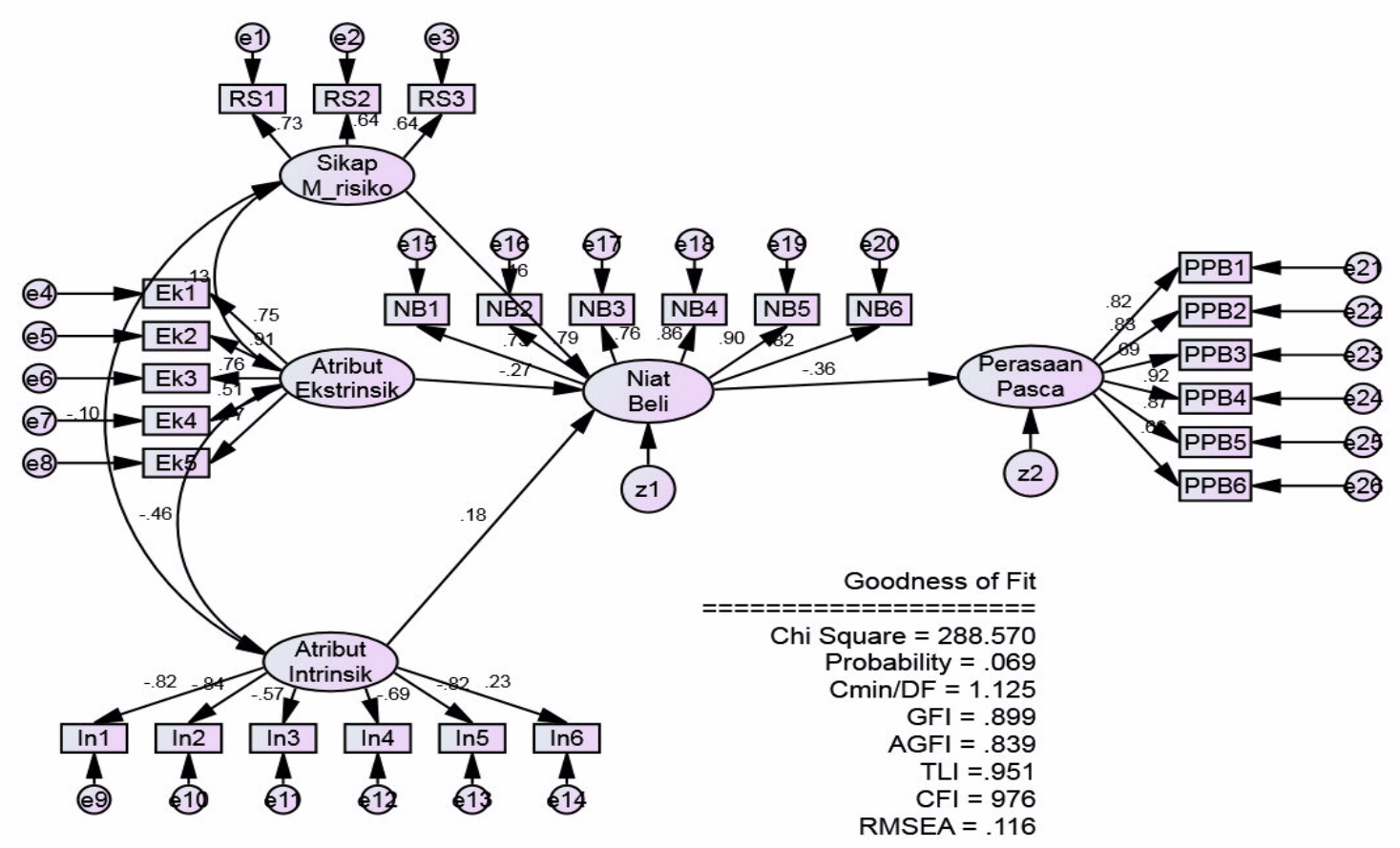

Gambar 2: Model Penelitian untuk Uji Hipotesis 
Tabel 2: Hasil Estimasi Uji Hipotesis untuk Software Komputer Bajakan

\begin{tabular}{lllcccc}
\hline & & & $\begin{array}{c}\text { Koef. } \\
\text { Standardized }\end{array}$ & S.E. & C.R. & P \\
\hline Niat_Beli & $\leftarrow$ & Sikap_M_risiko & -.228 & .098 & -2.449 & .014 \\
Niat_Beli & $\leftarrow$ Atribut_Ekstrinsik & .368 & .146 & 3.638 & $* * *$ \\
Niat_Beli & $\leftarrow$ Atribut_Intrinsik & -.238 & .456 & -1.859 & .063 \\
Perasaan_P_Beli & $\leftarrow$ Niat_Beli & -.374 & .083 & -3.941 & $* * *$ \\
\hline
\end{tabular}

Ket: signifikan pada $\alpha=5 \% * * *$ signifikan pada $p$-value 0,000

Sumber: Data Primer yang Diolah, 2013

Model yang digunakan untuk uji hipotesis merupakan model final yang telah melalui uji loading factor dan Goodness of Fit Test dan telah dinyatakan memenuhi syarat untuk dapat dilakukan uji hipotesis. Hasil model final yang digunakan dalam uji hipotesis ditunjukkan pada Gambar 2.

Hipotesis penelitian dilakukan uji satu sisi, karena hubungan antar variabel independen dengan variabel dependen dihipotesiskan berpengaruh positif dan pegaruh negatif. Untuk mengetahui apakah hipotesis didukung oleh data atau tidak, maka nilai probabilitas dari Critical Ratio (C.R) dibandingkan dengan $\alpha=5 \%$. Apabila Standardized Koefisien parameter bernilai positif dan nilai probabilitas dari Critical Ratio (C.R) kurang dari $\alpha=5 \%$, maka dapat disimpulkan bahwa hipotesis penelitian didukung oleh data (terbukti secara signifikan). Berdasarkan analisis statistik dengan menggunakan program AMOS, diperoleh hasil uji hipotesis yang merupakan uji hubungan kausalitas dari masing-masing variabel penelitian sebagaimana disajikan pada table 2 dan table 3.

Dari hasil pengujian dengan analisis Jalur (SEM) dapat diketahui koefisien atribut ekstrinsik produk terhadap niat beli adalah sebesar 0,368 dengan nilai $p$-value $(0,000<$ $0,05)$. Hal ini berarti atribut ekstrinsik produk terbukti berpengaruh positif dan signifikan terhadap niat beli software bajakan. Dengan demikian hipotesis pertama (H1a) dalam penelitian ini diterima. Selanjutnya, hasil pengujian menunjukkan bahwa koefisien atribut intrinsik produk terhadap niat beli adalah sebesar $-0,238$ dengan nilai p-value $(0,063>0,05)$, yang menandakan bahwa hipotesis kedua (H2a) dalam penelitian ini tidak terbukti. Lalu, koefisien untuk sikap menolak resiko terhadap niat beli adalah sebesar $-0,228$ dengan nilai $p$-value $(0,014<$ $0,05)$. Hal ini berarti hipotesis ketiga (H3a) dalam penelitian ini terbukti. Lebih lanjut, koefisien untuk niat beli produk bajakan terhadap perasaan bersalah paska beli adalah sebesar $-0,374$ dengan nilai $p$-value $(0,000<$ $0,05)$, hasil tersebut menunjukkan bahwa semakin tinggi niat beli konsumen atas software bajakan, maka semakin rendah perasaan bersalah paska beli produk tersebut yang berarti hipotesis keempat (H4a) dalam penelitian ini terbukti.

Tabel 3: Hasil Estimasi Uji Hipotesis untuk CD Musik Bajakan

\begin{tabular}{lllcccc}
\hline & & & $\begin{array}{c}\text { Koef. } \\
\text { Standardized }\end{array}$ & S.E. & C.R. & P \\
\hline Niat_Beli & $\leftarrow$ & Sikap_M_risiko & -.157 & .122 & 1.482 & .138 \\
Niat_Beli & $\leftarrow$ & Atribut_Ekstrinsik & .266 & .107 & -2.430 & .015 \\
Niat_Beli & $\leftarrow$ & Atribut_Intrinsik & -.182 & .373 & 1.421 & .155 \\
Perasaan_P_Beli & $\leftarrow$ & Niat_Beli & -.363 & .089 & -3.749 & $* * *$ \\
\hline
\end{tabular}

Ket: signifikan pada $\alpha=5 \% * * *$ signifikan pada $p$-value 0,000

Sumber: Data Primer yang Diolah, 2013 
Dari hasil pengujian dapat diketahui koefisien atribut ekstrinsik produk terhadap niat beli adalah sebesar 0,266 dengan nilai p-value $(0,015<0,05)$. Hal ini berarti atribut ekstrinsik produk memiliki pengaruh positif yang signifikan terhadap niat beli CD musik bajakan. Dengan demikian hipotesis pertama (H1b) dalam penelitian ini terbukti. Selanjutnya, hasil pengujian menunjukkan bahwa koefisien atribut intrinsik produk terhadap niat beli CD musik bajakan adalah sebesar -0,182 dengan nilai p-value $(0,155>0,05)$ yang menandakan bahwa hipotesis kedua (H2b) dalam penelitian ini tidak terbukti. Sikap menolak resiko tidak terbukti memiliki pengaruh yang signifikan pada niat beli CD musik bajakan, hal ini dapat dilihat dari hasil koefisien sebesar -0,157 dengan nilai $\mathrm{p}$-value $(0,138>0,05)$, sehingga hipotesis ketiga $(\mathrm{H} 3 \mathrm{~b})$ dalam penelitian ini tidak terbukti. Hipotesis terakhir pada penelitian ini $(\mathrm{H} 4 \mathrm{~b})$ dinyatakan terbukti berdasarkan hasil koefisien niat beli terhadap perasaan bersalah paska beli sebesar $-0,363$ dengan nilai $p$-value $(0,000<0,05)$.

\section{PEMBAHASAN}

Pada hasil studi ini, berdasarkan penilaian responden atas pembelian produk software komputer bajakan memperlihatkan bahwa variabel sikap menolak resiko dan atribut ekstrinsik produk terbukti berpengaruh signifikan terhadap niat beli produk software bajakan. Sehingga dapat dikatakan bahwa semakin tinggi konsumen mempertimbangkan resiko, maka semakin rendah niat konsumen membeli software bajakan dan berlaku hal yang sama pada perilaku konsumen terhadap atribut ekstrinsik produk. Namun hal ini tidak nampak pada perilaku konsumen terhadap CD musik bajakan. Pada perilaku konsumen terhadap CD music bajakan, hanya atribut ekstrinsik produk yang terbukti memiliki pengaruh positif yang signifikan terhadap niat beli. Hal ini dimungkinkan karena pada CD musik bajakan, konsumen cenderung tidak memperhitungkan resiko yang melekat pada produk tersebut (Olson and Jacoby 1972). Selanjutnya, hal berbeda terjadi pada perilaku konsumen yang dipengaruhi oleh atribut intrinsik produk.
Dalam penelitian ini, atribut intrinsic produk tidak terbukti memiliki pengaruh terhadap niat beli konsumen, baik pada CD musik maupun pada software computer bajakan. Akan tetapi, kontras dengan hal ini, niat beli justru terbukti memberikan pengaruh negative yang signifikan terhadap perasaan bersalah paska beli $\mathrm{CD}$ music maupun software computer bajakan.

Perbedaan karakteristik perilaku konsumen secara relatif dapat disebabkan oleh kemampuan produk untuk memberikan nilai tambah pada aktifitas yang dilakukan, khususnya pada saat konsumen mencari leisure time dimana konsumen cenderung memiliki keterlibatan yang lebih tinggi dalam melakukan evaluasi terhadap informasi yang diterima pada perilaku penggunaan CD musik. Adapun hal ini terlihat dari kajian para ahli yang secara umum mengungkapkan peranan variabel ekstrinsik terhadap dalam mempengaruhi keputusan keputusan konsumen terhadap kualitas fisik yang ditawarkan pada produk yang akan dikonsumsi seperti yang diungkapkan oleh Olson (1972) bahwa indikator kualitas dapat juga dilihat dari ekstrinsik dan intrinsik produknya. Dan penelitian sejenis lainya juga menunjukkan hasil yang sama terhadap peranan kualitas ekstrinsik dan intrinsik dalam memahami persepsi konsumen terhadap kualitas produk yang dihasilkan (Richardson et al., 1994). Selanjutnya, benar terbukti bahwa niat beli yang tinggi akan dapat menekan perasaan bersalah paska beli CD musik bajakan, seperti halnya yang terjadi pada pembelian software bajakan. Adapun cukup variatifnya tingkat signifikansi terhadap variabel yang diukur disebabkan oleh ketertarikan responden terhadap $\mathrm{CD}$ music bajakan merupakan implikasi dunia hiburan merupakan komiditi yang paling menarik dan menghibur bagi responden untuk dikonsumsi. Secara relatif, hal ini juga memiliki implikasi terhadap esensi individu secara psikologis, pada tingkatan kepentingan dan kebutuhan yang berbeda dimana hal tersebut pasti memiliki pendekatan yang berbeda dalam mencari alternatif fasilitas ataupun sumber informasi media yang relevan khususnya terhadap alternatif ekspektasi yang diharapkan. Musik merupakan bahasa universal 
dan dinikmati di seluruh kalangan dan lapisan masyarakat di seluruh dunia. Musik dapat menghilangkan beban pikiran dan mendengarkan musik yang sesuai dengan suasana hati dapat memberikan kepuasan tersendiri bagi sebagian orang.

\section{PENUTUP}

Aspek menolak resiko dan atribut ekstrinsik terlihat jelas berpengaruh pada niat beli konsumen terhadap software komputer bajakan. Atribut ekstrinsik juga terbukti memiliki pengaruh signifikan pada niat beli konsumen terhadap CD musik bajakan. Sehingga dapat dikatakan bahwa atribut ekstrinsik sangat relevan menjadi konsiderasi pembelian konsumen untuk produk bajakan yang bersifat high invole ment product (Software Komputer) dan low involvement product (CD lagu). Konsumen masih memandang atribut ekstrinsik sebagai poin penilaian penting sebelum memutuskan membeli produk bajakan. Mengingat responden di tanya tentang niat beli produk bajakan, maka atribut ekstrinsik sangat berpengaruh terhadap niat beli, mengingat mereka sadar bahwa kualitas secara intrinsik pasti rendah. Untuk mendapatkan kualitas yang tidak terlalu merugikan responden, maka mereka menggantungkan item yang mendorong mereka memiliki niat beli produk bajakan, seperti harga, penjual yang terpercaya, dan kemasannya yang baik.

Penelitian berkaitan dengan produk bajakan masih sangat relevan di lakukan di Indonesia. Apalagi Indonesia merupakan surga produk bajakan. Sehingga para ahli perlu melakukan penelitian ini untuk menjadi sumbangan kepada pemerintah dan pengusaha pemegang HaKI dalam upaya mengurangi bisnis produk bajakan atau mengurangi kemungkinan membahayakan konsumen karena bahan yang tidak berkualitas. Lalu, mengingat model dalam penelitian ini masih belum begitu kuat, maka peneliti ke depan dapat melakukan penelitian terkait dengan mereduksi atau menambah variabel yang berbeda tetapi ada dugaan variabel tersebut kuat mempengaruhi niat beli dan perasaan paska beli produk bajakan. Namun juga tidak menutup kemungkinan variabel-variabel lain yang berkaitan dengan brand bisa dimaksukkan dalam model yang telah dikembangkan ini karena konsumen Indonesia di duga masih menganggap superior brand luar negeri dan belum bisa memaknai arti sebuah brand sebagai identitas pemiliknya.

\section{DAFTAR PUSTAKA}

Lynch, S. 2002. Commercial Counterfeiting, Paper prepared for Trade Inspections Conference, October 23, 1-23.

Ang, S. H., P. S. Cheng, E. A. C. Lim and S. K. Tambyah. 2001. Spot the difference: Consumer response towards counterfeits. Journal of Consumer Marketing. 18(3).

219-235. http://dx.doi.org/10.1108/07363760110 39296

Phau, I., G. Prendergast and L. H. Chuen. 2001. Profiling brand-piracy-prone consumers: An exploratory study in Hongkong's clothing industry. Journal of Fashion Market ing and Management. 5 (1). 45-55.

Chakraborty, G., A. T. Alfred and T. Bristol. 1996. Exploring Consumers' Evaluations of Counterfeits: The Roles of Country of Origin and Ethnocentrism. In Advances in Consumer Research. 23. 379-384.

Chakraborty G, A. Allred, A.S. Sukhdial and T. Bristol. 1997. Use of negative cues to reduce demand for counterfeit products, Advance Consumer Research. 24(1). 345-9

Delener,N. 2000. International Counterfeit Marketing: Success without Risk. Review of Business (spring).16-20.

Harvey, M. G. and I. A. Ronkainen. 1985. International Counterfeiters: Marketing Success Without the Cost or The Risk. Columbia Journal of World Business. 20 (Fall). 37-45.

Chaudhry, P. E. and M. G. Walsh. 1996. An assessment of the impact of counterfeiting in international markets: The 
Piracy Paradox Persists. The Columbia Journal of World Business, Fall, p. 34-48.

Ajzen, I. and M. Fishbein. 1980. Understanding Attitudes And Predicting Social Behaviour. Englewood Cliffs, NJ.: Prentice-Hall.

Leavitt, H. J. 1954. A Note on Some Experimental Findings About the Meaning of Price. Journal of Business, 27 (July), 205-210

Allison, R. I. and K. P. Uhl. 1964. Influence of beer brand identification on taste perception. Journal of Marketing Research. 1. 36-39.

McDaniel, C. and R.C. Baker. 1977. Convenience Food Packaging and the Perception of Product quality. Journal of Marketing. 41. 57-58.

Wheatleay, J. and J. Chiu. 1977. The effects of price, store image, and product and respondents characteristic on perceptions of quality. Journal of Marketing Research. 14. 181-186.

Olson, J. C., and J. Jacoby. 1972. Cue utilization in the quality perception process. In Proceedings of the Third Annual Conference of the Association for Consumer Research, ed. M. Venkatesan, Chicago: Association for Consumer Research, Chicago. 167-179.

Olson, J. C. 1972. Product Quality Perception: A Model of Quality Cue Utilization and an Empirical Test. Unpublished doctoral dissertation, Purdue University.

Bauer, R. A. 1960. Consumer behavior as risk-taking. In R. S. Hancock (Ed.), Dynamic marketing for a changing world. Chicago: American Marketing Association. 389-398.

Cox, D.F. 1967. Risk-taking and information-handling in consumer behavior. Boston: Harvard University Press
Roselius, T. 1971. Consumer rankings of risk reduction methods. Journal of Marketing. 35. 56-61.

Jacoby, J. and L. Kaplan. 1972. The components of perceived risk. In M. Venkatesan (Ed.). Proceedings of Third Annual Convention of the Association for Consumer Research. 382-393

Nia, A. and J. L. Zaichkowsky. 2000. Do Counterfeits devalue the ownership of luxury goods? Jounal of Product and Brand Management. 9 (7). 485-497.

Cordell, V. V., N. Wongtada and R. L. Kieschnik, Jr.1996. Counterfeit Purchase Inten tions: Role of Lawfulness Attitudes and Product Traits as Determinants, Journal of Business Research. 35. 41-53.

Huang, J.H., B.C.Y. Lee and S.H. Ho. 2004. Consumer attitude toward gray market goods. International Marketing Review. 21(6). 598-614.

Donthu, N. And A.Garcia. 1999. The Internet Shopper. Journal of Advertising Research. 39(3), 52-58.

Field, J.R. B. 2000. An Empirical Investigation of Consumers' Perceptions and Purchase Intentions of Counterfeit Products: A Means-End Chain Analysis. A PhD Dissertation. Mississippi State University (online). Available http://wwwlib.umi.com/dissertations/pre view_all/9991310.

Phau, I. and M. Teah. 2009. Devil wears (counterfeit) Prada: a study of antecedents and outcomes of attitudes towards counterfeits of luxury brands. Journal of Consumer Marketing. 26 (1). $15-27$.

De Matos, C.A., C.T. Ituassu and C.A.V. Rossi. 2007. Consumer attitudes toward counterfeits: a review and extension. Journal of Consumer Marketing. 24 (1). 36-47. 
Maldonado, C. and E.Hume. 2005. Attitudes toward Counterfeit Products: An ethical perspective. Journal of Legal, Ethical and Regulatory Issues. 8 (2). 105-117
Richardson, P. S., A. Dick and A. K. Jain. 1994. Extrinsic and intrinsic cue effects on perception of store brand quality. Journal of Marketing. 58. 28-36.

Sekaran, U. 2000. Research methods for business: A skill-building approach. 3 edn. New York: John Wiley\&Sons, Inc. 